\title{
Influence of the Salts Common in Alkali Soils upon the Growth of Rice Plant. V.
}

Can Barium and Strontium replace the Antagonistic Action of Calcium?

By

Koji Miyake.

In the previous papers, it was pointed out that the injurious action of the metallic ions upon the growth of rice seedlings is perfectly neutralized by the presence of calcium ion. It will be very interesting then to experiment with barium and strontium, which are similar to calcium in chemical properties, with a view of finding favorable action similar to that of calcium upon the neutralization of toxicity of other metallic ions. In order to determine this problem we have taken sodium and magnesium chloride as the toxic salts, and the following experiments were made :

\section{Experiment with $\mathbf{M g C l}_{2}$.}

20 beakers of about $5.5 \mathrm{~cm}$ diameter and $7 \mathrm{~cm}$ deep, served for the experiment. While 1 beaker which contains $30 \mathrm{cc}$ of distilled water, served as check, the other 19 beakers received $1 / 10 \mathrm{~N}$. $\mathrm{MgCl}_{2} 30 \mathrm{cc}, 1 / 10 \mathrm{~N}$. $\mathrm{MgCl}_{2} 25 \mathrm{cc}+1 / 10 \mathrm{~N} . \mathrm{CaCl}_{2} 5 \mathrm{cc}$, $1 / 10 \mathrm{~N} . \mathrm{MgCl}_{2} 20$ cc+1/10 N. $\mathrm{CaCl}_{2} 10$ cc, 1/10 N. $\mathrm{MgCl}_{2} 15$ cc $+1 / 10 \mathrm{~N}$. $\mathrm{CaCl}_{2} 15 \mathrm{cc}, 1 / 10 \mathrm{~N} . \mathrm{MgCl}_{2} 10 \mathrm{cc}+1 / 10 \mathrm{~N} . \mathrm{CaCl}_{2}$ 20 cc, $1 / 10$ N. $\mathrm{MgCl}_{2} 5$ cc $+1 / 10 \mathrm{~N}$. $\mathrm{CaCl}_{2} 25$ cc, $1 / 10 \mathrm{~N}$. $\mathrm{CaCl}_{2}$ 30 cc, $1 / 10 \mathrm{~N}$. $\mathrm{MgCl}_{2} 25 \mathrm{cc}+1 / 10 \mathrm{~N}$. $\mathrm{BaCl}_{2}$ 5 cc, $1 / 10 \mathrm{~N} . \mathrm{MgCl}_{2}$ $20 \mathrm{cc}+1 / 10 \mathrm{~N} . \mathrm{BaCl}_{2} 10 \mathrm{cc}, 1 / 10 \mathrm{~N} . \mathrm{MgCl}_{2} 15 \mathrm{cc}+1 / 10 \mathrm{~N} . \mathrm{BaCl}_{2}$ $15 \mathrm{cc}, 1 / 10 \mathrm{~N} . \mathrm{MgCl}_{2} 10 \mathrm{cc}+1 / 10 \mathrm{~N}$. $\mathrm{BaCl}_{2} 20 \mathrm{cc}, 1 / 10 \mathrm{~N}$. 
$\mathrm{MgCl}_{2} 5 \mathrm{cc}+1 / 10 \mathrm{~N} . \mathrm{BaCl}_{2} 25 \mathrm{cc}, 1 / 10 \mathrm{~N} . \mathrm{BaCl}_{2} 30 \mathrm{cc}, 1 / 10 \mathrm{~N}$. $\mathrm{MgCl}_{2} 25 \mathrm{cc}+1 / 10 \mathrm{~N}$. $\mathrm{SrCl}_{2} 5 \mathrm{cc}, 1 / 10 \mathrm{~N} . \mathrm{MgCl}_{2} 20 \mathrm{cc}+1 / 10 \mathrm{~N}$. $\mathrm{SrCl}_{2} 10 \mathrm{cc}, 1 / 10 \mathrm{~N} . \mathrm{MgCl}_{2} 15 \mathrm{cc}+1 / 10 \mathrm{~N} . \mathrm{SrCl}_{2} 15 \mathrm{cc}, 1 / 10 \mathrm{~N}$. $\mathrm{MgCl}_{2} 10 \mathrm{cc}+1 / 10 \mathrm{~N}$. $\mathrm{SrCl}_{2} 20 \mathrm{cc}, 1 / 10 \mathrm{~N}$. $\mathrm{MgCl}_{2} 5 \mathrm{cc}+1 / 10 \mathrm{~N}$. $\mathrm{SrCl}_{2} 25$ cc and $1 / 10 \mathrm{~N}$. $\mathrm{SrCl}_{2} 30$ cc respectively. Five seedlings, about $25 \mathrm{~mm}$ high, which were grown in distilled water from seeds of almost uniform size and specific gravity (1.185-1.200), were transplanted in each of the respective beakers on February 25 th (1913) and kept in the green house. The evaporated water was supplemented with distilled water from time to time so as to keep the culture solutions always in their initial concentration. On March 14th, the difference in development in the respective culture was very striking, and measurement was then made with the following result:

\begin{tabular}{|c|c|c|c|}
\hline Solutions used & $\begin{array}{l}\text { Length } \\
\text { of leaf }\end{array}$ & $\begin{array}{l}\text { Length } \\
\text { of root }\end{array}$ & $\begin{array}{l}\text { Number } \\
\text { of roots }\end{array}$ \\
\hline Distilled water 30 cc. & $\begin{array}{ll}\mathrm{mm} \\
68\end{array}$ & $\frac{\min }{60}$ & 8 \\
\hline 1/10 N. $\mathrm{MgCl}_{2} 30$ cс. & 53 & 12 & 1 \\
\hline $1 / 10$ N. $\mathrm{MgCl}_{2} 25$ cc. $+1 / 10 \mathrm{~N} . \mathrm{CaCl}_{2} 5$ cc. & 68 & 50 & 9 \\
\hline $1 / 10 \mathrm{~N} . \mathrm{MgCl}_{2} 20$ cc. $+1 / 10 \mathrm{~N} . \mathrm{CaCl}_{2} 10$ cc. & 65 & 40 & 10 \\
\hline $1 / 10$ N. $\mathrm{MgCl}_{2} 15$ cc. $+1 / 10$ N. $\mathrm{CaCl}_{2} 15$ cc. & 62 & 35 & 8 \\
\hline $1 / 10$ N. $\mathrm{MgCl}_{2} 10$ cc. $+1 / 10$ N. $\mathrm{CaCl}_{2} 20$ cc. & 60 & 20 & 8 \\
\hline $1 / 10$ N. $\mathrm{MgCl}_{2} 5$ cc. $+1 / 20$ N. $\mathrm{CaCl}_{2} 25$ cc. & 52 & 15 & 6 \\
\hline $1 / 10 \mathrm{~N} . \mathrm{CaCl}_{2} 30$ cc. & 44 & 12 & 8 \\
\hline $1 / 10 \mathrm{~N} . \mathrm{MgCl}_{2} 25$ cc. $+1 / 10 \mathrm{~N} . \mathrm{BaCl}_{2} 5$ cc. & 40 & 12 & 1 \\
\hline $1 / 10$ N. $\mathrm{MgCl}_{2} 20$ cc. $+1 / 10$ N. $\mathrm{BaCl}_{2} 10$ cc. & 33 & 10 & 1 \\
\hline $1 / 10$ N. $\mathrm{MgCl}_{2} 15$ cc. $+1 / 10$ N. $\mathrm{BaCl}_{2} 15$ cc. & 28 & 8 & 1 \\
\hline $1 / 10$ N. $\mathrm{MgCl}_{2} 10$ cc. $+1 / 10$ N. $\mathrm{BaCl}_{2} 20$ cc. & 28 & 7 & 1 \\
\hline $1 / 10$ N. $\mathrm{MgCl}_{2} 5$ cc. $+1 / 10$ N. $\mathrm{BaCl}_{2} 25$ cc. & 28 & 5 & 1 \\
\hline $1 / 10$ N. $\mathrm{BaCl}_{2} 30$ ce. & 24 & 8 & 1 \\
\hline $1 / 10$ N. $\mathrm{MgCl}_{2} 25$ cc. $+1 / 10 \mathrm{~N} . \mathrm{SrCl}_{2} 2$ cc. & 60 & 12 & 3 \\
\hline $1 / 10$ N. $\mathrm{MgCl}_{2} 20$ cc. $+1 / 10$ N. $\mathrm{SrCl}_{2} 10$ cc. & 45 & 8 & 3 \\
\hline $1 / 10$ N. $\mathrm{MgCl}_{2} 15$ cc. $+1 / 10 \mathrm{~N} \cdot \mathrm{SrCl}_{2} 15$ cc. & 40 & 5 & 2 \\
\hline $1 / 10$ N. $\mathrm{MgCl}_{2} 10$ cc. $+1 / 10$ N. $\mathrm{SrCl}_{2} 20$ cc. & 35 & 7 & 1 \\
\hline $1 / 10$ N. $\mathrm{MgCl}_{2} 5$ cc. $+1 / 10$ N. $\mathrm{SrCl}_{2} 25$ cc. & 30 & 9 & 1 \\
\hline $1 / 10 \mathrm{~N} . \mathrm{SrCl}_{2} 30 \mathrm{ce}$. & 22 & 8 & 1 \\
\hline
\end{tabular}


The result shows that the presence of calcium in proper proportion can exert only a beneficial action, while in the case of barium, on the contrary, a depression resulted. Although strontium in suitable proportion retarded the toxic action of magnesium, it is far inferior to calcium.

\section{Experiment with $\mathbf{N a C l}$.}

20 beakers, each containing 30 cc of culture fluids, served for the experiment. The culture solutions were applied in the same proportion as in Experiment $\mathrm{I}$ using $\mathrm{NaCl}$ instead of $\mathrm{MgCl}_{2}$.

Five seedlings, about $20 \mathrm{~mm}$ high, were transplanted on March 7th (1913) and kept in the green house. The evaporated water was supplemented with distilled water from time to time

\begin{tabular}{|c|c|c|c|}
\hline Solutions used & $\begin{array}{l}\text { Length } \\
\text { of leaf }\end{array}$ & $\begin{array}{l}\text { Length } \\
\text { of root }\end{array}$ & $\begin{array}{l}\text { Number } \\
\text { of roots }\end{array}$ \\
\hline Distilled water $30 \mathrm{cc}$. & 65 & $\frac{\operatorname{mim}}{50}$ & 9 \\
\hline $1 / 10$ N. $\mathrm{NaCl} 30 \mathrm{cc}$. & 44 & 13 & 1 \\
\hline $1 / 10$ N. $\mathrm{NaCl} 25$ cc. $+1 / 10 \mathrm{~N} \cdot \mathrm{CaCl}_{2} 5$ cc. & 70 & 40 & 9 \\
\hline $1 / 10$ N. $\mathrm{NaCl} 20$ cc. $+1 / 10$ N. $\mathrm{CaCl}_{2} 10$ ce. & 70 & 40 & 9 \\
\hline $1 / 10$ N. $\mathrm{NaCl} 15$ cc. $+1 / 10$ N. $\mathrm{CaCl}_{2} 15$ cc. & 60 & 25 & 8 \\
\hline $1 / 10$ N. $\mathrm{NaCl} 10$ cc. $+1 / 10$ N. $\mathrm{CaCl}_{2} 20$ cc. & 56 & 20 & 8 \\
\hline $1 / 10$ N. $\mathrm{NaCl} 5$ cc. $+1 / 10$ N. $\mathrm{CaCl}_{2} 25$ cc. & 50 & 20 & 6 \\
\hline $1 / 10 \mathrm{~N} . \mathrm{CaCl}_{2} 30 \mathrm{cc}$. & 44 & 22 & 6 \\
\hline $1 / 10$ N. $\mathrm{NaCl} 25$ cc. $+1 / 10$ N. $\mathrm{BaCl}_{2} 5 \mathrm{cc}$ & 40 & 20 & 3 \\
\hline $1 / 10 \mathrm{~N} . \mathrm{NaCl} 20$ cc. $+1 / 10$ N. $\mathrm{BaCl}_{2} 10$ cc. & 41 & 18 & 5 \\
\hline $1 / 10$ N. $\mathrm{NaCl} 15$ cc. $+1 / 10$ N. $\mathrm{BaCl}_{2} 15$ cc. & 30 & 15 & 3 \\
\hline $1 / 10$ N. $\mathrm{NaCl} 10 \mathrm{cc}+1 / 10$ N. $\mathrm{BaCl}_{2} 20 \mathrm{cc}$ & 30 & 20 & 3 \\
\hline $1 / 10$ N. $\mathrm{NaCl} 5$ cc. $+1 / 10$ N. $\mathrm{BaCl}_{2} 25$ cc. & 28 & 17 & 3 \\
\hline $1 / 10$ N. $\mathrm{BaCl}_{2} 30 \mathrm{cc}$. & 29 & 10 & 3 \\
\hline $1 / 10$ N. $\mathrm{NaCl} 25$ cc. $+1 / 10$ N. $\mathrm{SrCl}_{2} 5$ cc. & 50 & 22 & 6 \\
\hline $1 / 10 \mathrm{~N} . \mathrm{NaCl} 20 \mathrm{cc}+1 / 10 \mathrm{~N} . \mathrm{SrCl}_{2} 10$ cc. & 47 & 20 & 4 \\
\hline $1 / 10 \mathrm{~N} . \mathrm{NaCl} 15$ cc. $+1 / 10 \mathrm{~N} . \mathrm{SrCl}_{2} 15$ cc. & 45 & 16 & 5 \\
\hline $1 / 10$ N. $\mathrm{NaCl} 10$ cc. $+1 / 10$ N. $\mathrm{SrCl}_{2} 20$ cc. & 40 & 10 & 4 \\
\hline $1 / 10 \mathrm{~N} . \mathrm{NaCl} 5$ cc. $+1 / 10$ N. $\mathrm{SrCl}_{2} 25$ cc. & 36 & 16 & 4 \\
\hline $1 / 10 \mathrm{~N} . \mathrm{SrCl}_{2} 30 \mathrm{cc}$ & 28 & 15 & 3 \\
\hline
\end{tabular}


as in the preceding experiment. The plants had developed very well with remarkable difference in growth. The plants were measured on March 24th with the following result which coincides with that of the preceding experiment.

\section{Result.}

The injurious effect of the metallic ions upon the growth of rice seedlings is perfectly counteracted only by the presence of calcium ion while strontium ion can exert an influence only slightly retarding the toxicity of the metallic ions. Barium ion not only has no beneficial action, but a depressing effect is observed. Consequently, it is concluded that barium and strontium could not replace the antagonistic action of calcium.

Chemical Laboratory, College of Agriculture, ToHoku Imperial University, SAPporo, JAPAN.

July, 1913. 